\title{
Characterization of Hepatitis B Virus Molecular Genotypes in Chongqing and Quantitative Serological Markers in Patients during Natural Phases of Chronic Hepatitis B Infection
}

\author{
YuXiang Shifeng Huang Jirong Xia Diqing Ye Pu Chen Liping Zhang \\ Department of Clinical Laboratory, The First Affiliated Hospital of Chongqing Medical University, \\ Chongqing, PR China
}

\section{Key Words}

Hepatitis B virus genotype - Quantitative immunoassays •

Hepatitis B infection • Epidemiology

\begin{abstract}
Background/Aims: The present study was launched to systematically characterize the molecular genotypes and quantitative serological biomarkers during the natural course of chronic hepatitis $B(\mathrm{CHB})$ infection in a patient population from Chongqing, China. Methods: A total of 140 patients were enrolled and grouped according to the natural phases of HBV infection: $\mathrm{HBeAg}(+)$ immune tolerance, immune clearance, $\mathrm{HBeAg}(-)$ low replicative and reactivation phase. Nested PCR was used for HBV molecular genotyping and chemiluminescent microparticle immunoassay for quantitative serological detection. Results: Subgenotypes B2 and C2 were found to be most prevalent with genotype $B$ patients showing more potent viral activity. $\mathrm{HBs} A g$ level was found to be significantly correlated with HBV DNA, HBeAg, age, ALT and AST levels during some phases of CHB. Conclusion: These results indicated that molecular genotyping and quantitative serological detection might be helpful for earlier prediction of the long-term disease outcomes.
\end{abstract}

\section{KARGER}

Fax +4161306 1234

E-Mail karger@karger.ch

www.karger.com
(C) 2011 S. Karger AG, Basel

0300-5526/12/0551-0068\$38.00/0

Accessible online at:

www.karger.com/int
Hepatitis B virus (HBV) infection is an important worldwide public health problem and the major cause of chronic hepatitis, cirrhosis and hepatocellular carcinoma [1]. HBV replication persists throughout the course of chronic infection, and host immune response plays a pivotal role in HBV-related liver damage and control of $\mathrm{HBV}$ replication. On the basis of the interplay between virus and host, the natural history of chronic hepatitis $\mathrm{B}(\mathrm{CHB})$ patients was divided into four dynamic phases [2]: the first immune tolerance (IT) phase is characterized by extremely high serum HBV DNA levels and positive HBeAg with low hepatitis activities as reflected by normal serum transaminase level despite active HBV replication. After 20-30 years of persistent infection, the second immune clearance (IC) phase ensues, during which the liver cells suffer continuous damage due to immune-mediated cytotoxic response towards infected hepatocytes. However, after these immune attacks, HBV replication is temporarily suppressed. The third low replicative (LR) phase is characterized by the absence of $\mathrm{HBeAg}$, presence of anti-HBe, persistently normal serum transaminase levels and low or

Y.X. and S.H. contributed equally to this work. 
Fig. 1. Representative PCR amplification products of different HBV genotypes as determined by nested PCR. Nested PCR was performed in two rounds. Agarose gel electrophoresis was performed after nested PCR, and the representative amplification products of various HBV genotypes are shown. $\mathrm{M}=\mathrm{DNA}$ molecular marker; lanes 1, 2 = B/C2 genotype; lanes 3, $4=$ negative control; lanes $5,6=\mathrm{C} 2$ genotype; lanes $7,8=\mathrm{B} 2$ genotype; lanes $9,10=\mathrm{B}$ genotype.

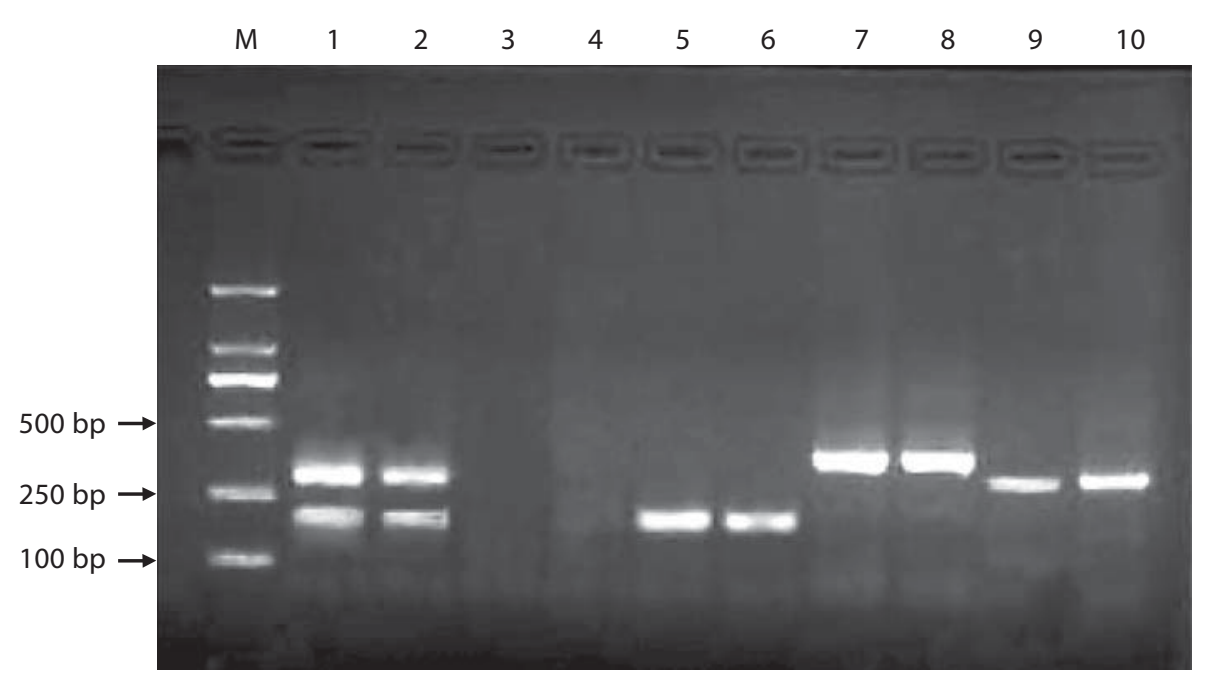

undetectable serum HBV DNA by PCR. HBV could also replicate in the absence of $\mathrm{HBeAg}$, hence the fourth reactivation (RE) phase was observed, which may occur spontaneously or as a result of immunosuppression.

Advances in understanding the natural history of HBV infection suggest that in addition to serum HBV DNA level, various factors including levels of circulating $\mathrm{HBs} \mathrm{Ag}$ and $\mathrm{HBeAg}$ and $\mathrm{HBV}$ genotypes may contribute to disease progression and patients' response to antiviral therapy [3]. However, additional work is needed to validate these assays before they can be considered to be of true diagnostic value, and further evaluation is needed to decide which will have the greatest clinical applicability. Natural history studies of CHB have shown that loss of HBs Ag is associated with improved survival and reduced risk of HCC, indicating that HBsAg loss is clearly a reliable marker of surrogate therapeutic endpoint [4]; however, its relatively rare occurrence limits its utility for evaluation of new therapies, thus a better understanding of the factors related to HBsAg level is urgently needed. HBV genome evolves due to the high error rate of the viral reverse transcriptase, and a long period of HBV evolution leads to the occurrence of various genotypes and subgenotypes, which may influence disease progression and response to therapy [5]; however, many of the studies that have included genotype assessment do not compare across the range of genotypes during the natural course of $\mathrm{CHB}$, and genotype determination was not incorporated into the current management guidelines.

The present study was designed to systematically characterize the molecular genotypes and quantitative serology during the natural phases of $\mathrm{CHB}$ in order to evaluate the dynamic changes of various biomarkers and to further explore their possible clinical utilities.

140 currently untreated mono-infected $\mathrm{CHB}$ patients, including 86 males (61.4\%) and 54 females (38.6\%) with a mean age of $30.34 \pm 10.63$ years (9-74 years), from The First Affiliated Hospital of Chongqing Medical University, were enrolled into the present study and informed written consent was obtained from all the subjects. All the procedures of this study were performed according to the World Medical Association Declaration of Helsinki and approved by the Ethics Committee of Chongqing Medical University.

Molecular genotyping for genotypes A-D and subgenotypes $\mathrm{B} 1, \mathrm{~B} 2, \mathrm{C} 1$ and $\mathrm{C} 2$ was performed according to a nested PCR method previously established by Jin et al. [6], followed by genetic confirmation through bidirectional DNA sequencing. Serum HBsAg and HBeAg levels were quantified using the quantitative Abbott Architect i2000 Assay (Abbott Diagnostics, Abbott Park, Ill., USA). The serum HBV DNA levels were quantified by real-time quantitative PCR with a linear range of $10^{3}-10^{8}$ copies/ $\mathrm{ml}$, and ALT and AST were detected by automatic biochemistry analyzer. $\mathrm{CHB}$ patients were categorized according to the phase of persistent HBV infection: IT ( $\mathrm{n}=$ $29)$, IC $(n=55), \operatorname{LR}(\mathrm{n}=21)$ and RE $(\mathrm{n}=35)$.

Agarose gel electrophoresis-based genotyping was performed after nested PCR, and the representative amplification products of various $\mathrm{HBV}$ genotypes are shown in figure 1. Among all the 140 serum samples, a total of 123 samples were successfully genotyped and subgenotypes B2 $(85 / 123,69.1 \%)$ and $\mathrm{C} 2(27 / 123,22.0 \%)$ were found to be the most prevalent forms in southwestern 
Table 1. Characterization of HBV molecular genotypes among patients with different serum HBV DNA level strata

\begin{tabular}{|c|c|c|c|c|c|c|c|c|c|}
\hline HBV DNA & $\begin{array}{l}\text { Number of } \\
\text { detections }\end{array}$ & $\begin{array}{l}\text { Number } \\
\text { of typing }\end{array}$ & \multicolumn{7}{|c|}{ Number of genotypes ( $\%$ of the column) } \\
\hline $1 \times 10^{4.5-6.5} \mathrm{IU} / \mathrm{ml}$ & 36 & 36 & 0 & 0 & $20(23.53)$ & 0 & $13(48.15)$ & 0 & $2(18.18)$ \\
\hline $1 \times 10^{6.5} \mathrm{IU} / \mathrm{ml}$ & 70 & 70 & 0 & 0 & $54(63.53)$ & 0 & $8(29.63)$ & 0 & $9(81.82)$ \\
\hline
\end{tabular}

Table 2. The correlation of log DNA, HBsAg, HBeAg and ALT with HBV subgenotypes

\begin{tabular}{|c|c|c|c|c|c|c|c|c|}
\hline \multirow[t]{2}{*}{ Subgenotype } & \multicolumn{2}{|c|}{ log DNA, copies/ml } & \multicolumn{2}{|c|}{$\mathrm{HBsAg}, \mathrm{IU} / \mathrm{ml}$} & \multicolumn{2}{|c|}{ HBeAg, S/CO } & \multicolumn{2}{|c|}{ ALT, U/1 } \\
\hline & $\mathrm{R}$ & $\mathrm{p}$ & $\mathrm{R}$ & $\mathrm{p}$ & $\mathrm{R}$ & $\mathrm{p}$ & $\mathrm{R}$ & $\mathrm{p}$ \\
\hline $\mathrm{B} 2$ & 0.970 & 0.157 & 1.000 & $0.015^{*}$ & 1.000 & $0.013^{*}$ & 0.970 & 0.155 \\
\hline $\mathrm{C} 2$ & 0.219 & 0.859 & -0.191 & 0.878 & -0.113 & 0.928 & 0.999 & $0.024^{*}$ \\
\hline
\end{tabular}

* Significant correlation was found between HBV subgenotype and level of the indicated marker.

Table 3. Correlations of HBV DNA, HBeAg, ALT, AST and age with HBsAg in the IT, IC, LR and RE groups

\begin{tabular}{|c|c|c|c|c|c|c|c|c|}
\hline HBsAg vs. & $\mathrm{R}$ & $\mathrm{p}$ & $\mathrm{R}$ & $\mathrm{p}$ & $\mathrm{R}$ & $\mathrm{p}$ & $\mathrm{R}$ & $\mathrm{p}$ \\
\hline HBeAg & -0.165 & 0.392 & 0.402 & $0.002^{*}$ & -0.151 & 0.514 & -0.075 & 0.668 \\
\hline ALT & -0.011 & 0.957 & 0.047 & 0.731 & 0.087 & 0.708 & 0.985 & $0.001^{*}$ \\
\hline AST & -0.447 & $0.015^{*}$ & 0.023 & 0.865 & -0.302 & 0.183 & 0.992 & $0.001^{*}$ \\
\hline
\end{tabular}

* Significant correlation was found between HBsAg level and level of the indicated marker.

China, while no patients were found to be with genotype $\mathrm{A}, \mathrm{B} 1, \mathrm{C} 1$ or $\mathrm{D}$ (table 1). Furthermore, when patients were divided into three strata according to HBV DNA levels, significant differences in subgenotype distribution were found among patients in the three HBV DNA strata $\left(\chi^{2}=13.054, p=0.011\right)$. In general, patients infected with genotypes B2 and MIX (B/C2) tend to be infected with high levels of HBV DNA load (64 and 81\% with >1 $\times 10^{6.5}$ copies/ml viral DNA, respectively), and those with genotype $\mathrm{C} 2$ tend to show intermediate $\mathrm{HBV}$ viremia $\left(\sim 48 \%\right.$ with $1 \times 10^{4.5-6.5}$ copies/ml viral DNA) (table 1$)$.

When patients were divided into four subgroups on the basis of the natural courses of $\mathrm{CHB}$, no statistical sig- nificance was found in genotype distribution among the IT, IC, RE and RE phases $\left(\chi^{2}=5.094, p=0.532\right)$.

HBV genotypes were previously reported to be correlated with HBeAg seroconversion and liver disease activity $[5,7]$. In the present study, we further explored the possible correlation of HBV genotypes with log DNA and serum HBsAg, HBeAg and ALT, four well-acknowledged biomarkers important for the prediction of clinically relevant outcomes of CHB. While genotype $\mathrm{C} 2$ was demonstrated to be associated with elevated ALT $(\mathrm{R}=0.999, \mathrm{p}=$ $0.024)$, genotype $B 2$ was found to be closely correlated with elevated serum HBsAg and HBeAg levels as shown in table 2 . 
The variations of HBsAg levels in consecutive phases of $\mathrm{CHB}$ may reflect the natural course of infection. To further explore the factors that can predict HBsAg level during disease progression, the possible correlation of HBs Ag level with other well-known HBV activity predictors within each phase of infection was performed. As is shown in table 3, significant positive correlation was noticed between HBsAg levels and HBV DNA quantity in the IC, LR and RE groups $(\mathrm{R}=0.337, \mathrm{p}=0.012$; $\mathrm{R}=0.580$, $\mathrm{p}=0.006 ; \mathrm{R}=0451, \mathrm{p}=0.007$, respectively). Moreover, $\mathrm{HBsAg}$ was found to be positively correlated with $\mathrm{HBeAg}$ $(\mathrm{R}=0.402, \mathrm{p}=0.002)$ and reversely correlated with age $(\mathrm{R}=-0.280, \mathrm{p}=0.038)$ in the LC group. Interestingly, HBsAg showed a positive correlation with ALT level only within the RE group $(\mathrm{R}=0.985, \mathrm{p}=0.001)$, and while a reverse correlation between HBsAg and AST was found in the IT group ( $\mathrm{R}=-0.447, \mathrm{p}=0.015), \mathrm{HBsAg}$ was found to be positively correlated with AST in the RE group $(\mathrm{R}=$ 0.992, $\mathrm{p}=0.001$ ).

To sum up, the most important finding of this study was the identification of the most prevalent forms of subgenotypes (B2, C2 and B2/C2 mixed) in southwestern China and the characterization of the HBV molecular genotypes according to the quantitative serum $\mathrm{HBV}$ DNA level strata (table 1), natural courses of $\mathrm{CHB}$, and serum levels of log DNA, HBsAg, HBeAg and ALT (table 2), respectively. HBV genotypes were previously shown to have distinct geographic and ethnic distribution, with genotypes B and C prevailing in Southeast Asia [8], and our present study further confirmed this finding. Moreover, HBV genotypes were previously demonstrated to influence the natural course of liver disease progression in HBV carriers in Asian countries [9]. Interestingly, in the present study, HBV genotypes showed no significant distribution differences among patients in various disease phases, but we did find significant difference in the genotypic distribution of HBV subgenotypes among patients in the low, intermediate and high HBV DNA strata for the first time. In addition, genotype $\mathrm{C}$ was previously demonstrated to be an independent factor predictive of ALT elevations as well as HBV reactivation [10], while $\mathrm{HBV}$ patients with genotype B were previously shown to have early and frequent HBeAg seroconversion and less progressive liver disease compared with genotype $\mathrm{C}$ by Chu et al. [11]. In contrast, in the present study, genotype $\mathrm{B}$ was demonstrated to be most frequently distributed in the highest DNA level stratum (table 1), closely associated with elevated serum HBsAg and $\mathrm{HBeAg}$ (table 3), indicating more potent viral activity in patients with genotype B. Because genotype B patients showed a higher frequency of $\mathrm{HBeAg}$ positivity than genotype $\mathrm{C}$ patients in our study, it is not surprising to see that the former patients have a higher viral load than the latter patients. Although we cannot explain the discrepancy for the disease severity of genotype $\mathrm{B}$ and $\mathrm{C}$ between our results and that reported by Chu et al. [11], one possible explanation is that they conducted a longitudinal study of HBeAg-positive patients with normal aminotransferase levels at baseline, whereas we used a cross-sectional design with patients belonging to all the four natural phases of CHB infection. Though it would have been useful to follow patients longitudinally through different phases of infection, such longitudinal follow-up is difficult given that patients can remain in either the IT or LR phases for years, and patients in the IC and RE phases are potential treatment candidates. Another possibility is likely due to the major differences in demography or ethnicity of patients in different regions. On the other hand, it should be noted that though genotype $\mathrm{C}$ was confirmed to be associated with elevated ALT in the present study as was previously reported [10], our study suggests that genotype C2 was not associated with either HBV DNA or HBeAg level, which is just incongruent with prior reports [10].

The second finding of this study was the demonstration that $\mathrm{HBsAg}$ variations in consecutive phases of $\mathrm{CHB}$ reflected the natural course of $\mathrm{CHB}$, which was just concordant with recent researches in both European and Asian populations $[12,13]$.

In conclusion, the present study provides a detailed analysis about the molecular genotypic, virologic and quantitative serologic features of $140 \mathrm{HBV}$ patients during the natural phases of $\mathrm{CHB}$ in southwestern China. Subgenotypes B2 and C2 were found to be most prevalent, with genotype $\mathrm{B}$ patients showing more active viral activity. The HBsAg level was found to reflect serum HBV DNA content and virus productivity during the natural phases of CHB. However, these results should be considered cautiously given the relatively small number of recruited patients in each group. Further evaluation involving large-scale longitudinal studies with serial serum samples are definitively needed to further characterize and understand these mechanisms. However, based on the preliminary data of the present research, the use of HBV DNA genotyping and quantitative immunoassays may allow fine-tuning of treatment protocols. Thus, we do recommend a role for genotype determination and quantitative serology in the current management and treatment guidelines for $\mathrm{CHB}$. 


\section{Acknowledgements}

This work was supported in part by the National Science Foundation of China (Grant No. 81071621 and No. 30973378), the Natural Science Foundation of Chongqing, China (Grant No. CSTC, 2009BB5257 and No. CSTC, 2010BB5390), and the Medical Science Foundation of The First Affiliated Hospital of Chongqing Medical University (Grant No. YXJJ 2009-12).

\section{Disclosure Statement}

None.

\section{References}

1 Kao JH, Chen DS: Global control of hepatitis B virus infection. Lancet Infect Dis 2002;2: 395-403.

2 McMahon BJ: The natural history of chronic hepatitis B virus infection. Hepatology 2009; 49:S45-S55.

>3 Bowden DS, Thompson AJ: New developments in HBV molecular diagnostics and quantitative serology. Hepatol Int 2008; 2:S3-S11.

$\checkmark 4$ Feld JJ, Wong DKH, Heathcote EJ: Endpoints of therapy in chronic hepatitis B. Hepatology 2009;49:S96-S102.

5 Liu CJ, Kao JH, Chen DS: Therapeutic implications of hepatitis B virus genotypes. Liver Int 2005;25:1097-1107.

-6 Jin H, Wang J, Yan L, Nie JJ, Li J, Zhuang H: Establishment of a nested PCR to identify hepatitis $\mathrm{B}$ virus genotypes A-D and subgenotypes B1, B2, C1 and C2. Zhonghua Liu Xing Bing Xue Za Zhi 2008;29:1235-1239.
7 Livingston SE, Simonetti JP, Bulkow LR, Homan CE, Snowball MM, Cagle HH, Negus SE, McMahon BJ: Clearance of hepatitis B e antigen in patients with chronic hepatitis $B$ and genotypes A, B, C, D, and F. Gastroenterology 2007;133:1452-1457.

$>8$ Liu CJ, Kao JH: Hepatitis B genotype: what should the clinician know? Curr Hepatitis Rep 2007;6:17-23.

-9 Maeshiro T, Arakaki S, Watanabe T, Aoyama H, Shiroma J, Yamashiro T, Hirata T, Hokama A, Kinjo F, Nakayoshi T, Nakayoshi T, Mizokami M, Fujita J, Sakugawa H: Different natural courses of chronic hepatitis $\mathrm{B}$ with genotypes $\mathrm{B}$ and $\mathrm{C}$ after the fourth decade of life. World J Gastroenterol 2007;13: 4560-4565.

10 Chu CM, Liaw YF: Predictive factors for reactivation of hepatitis B following hepatitis B e antigen seroconversion in chronic hepatitis B. Gastroenterology 2007;133:1458-1465.
1 Chu CM, Liaw YF: Genotype C hepatitis B virus infection is associated with a higher risk of reactivation of hepatitis $B$ and progression to cirrhosis than genotype B: a longitudinal study of hepatitis B e antigen-positive patients with normal aminotransferase levels at baseline. J Hepatol 2005;43:411-417. 12 Jaroszewicz J, Calle Serrano B, Wursthorn K, Deterding K, Schlue J, Raupach R, Flisiak R, Bock CT, Manns MP, Wedemeyer H, Cornberg M: Hepatitis B surface antigen (HBsAg) levels in the natural history of hepatitis B virus (HBV)-infection: a European perspective. J Hepatol 2010;52:514-522.

13 Nguyen T, Thompson AJ, Bowden S, Croagh C, Bell S, Desmond PV, Levy M, Locarnini SA: Hepatitis B surface antigen levels during the natural history of chronic hepatitis $B$ : a perspective on Asia. J Hepatol 2010;52:508513. 